\title{
ESTIMATING SURFACE VELOCITIES IN THE SOUTHERN BRAZILIAN AND URUGUAYAN CONTINENTAL SHELVES USING THE MAXIMUM CROSS-CORRELATION METHOD
}

\author{
J. Costi ${ }^{\mathrm{a}}$, \\ E. P. Kirinus ${ }^{b}$, \\ W. C. Marques ${ }^{\mathrm{a}}$, \\ C. A. E. Garciab, \\ and C. Fujitab \\ ${ }^{a}$ Universidade Federal do Rio Grande \\ Instituto de Matemática, Estatística e Física \\ Av. Itália, km 8. Bairro Carreiros \\ CEP 96203-900, Rio Grande, RS, Brasil \\ ju.costi@gmail.com \\ ${ }^{\mathrm{b}}$ Universidade Federal do Rio Grande \\ Instituto de Oceanografia \\ Av. Itália, km 8. Bairro Carreiros \\ CEP 96203-900, Rio Grande, RS, Brasil \\ ABSTRACT \\ The present study investigates the viability of using the maximum cross- \\ correlation method on ocean color imagery to estimate surface velocities on \\ the Southern Brazilian and Uruguayan continental shelf. The method \\ searches for maximum correlation areas in two sequential images, \\ determining the displacement of oceanographic features within the time \\ interval of the images acquisition. We use the NWL550 parameter of \\ MODIS-Aqua imagery, once it is well correlated with the total suspended \\ matter in the water and provides relatively well-defined optical features on \\ the Southern Brazilian and Uruguayan continental shelves. The estimated \\ velocity fields showed a preferential direction northward, with average \\ intensities between $0.06 \mathrm{~m} / \mathrm{s}$ and $0.11 \mathrm{~m} / \mathrm{s}$. The frequent cloud coverage and \\ the diffusive processes restrict the number of image pairs suitable for the \\ analysis. Nevertheless, the method showed potential for investigating the \\ current velocity fields on the study area, as the estimates are in agreement \\ with the wind fields and the velocities' intensities are well within the values \\ previously described in the literature for the region. \\ Received: May 11, 2017 \\ Revised: June 12, 2017 \\ Accepted: July 12, 2017 \\ Keywords: coastal dynamics, ocean color, surface currents
}

\section{NOMENCLATURE}

MCC Maximum cross correlation

MODIS Moderate Resolution Imaging Spectroradiometer

NLW550 Normalized water-leaving radiance at 550 $\mathrm{nm}$

\section{INTRODUCTION}

The continental shelf is a region where local and remote atmospheric and oceanic forces interact with the coastal geomorphology and continental freshwater inputs, resulting in a highly dynamic system. The understanding of this system is of relevance for many human activities, such as renewable energy generation, oil exploration, fisheries and disposal of dredged material.

The southwestern portion of the Atlantic Ocean (Figure 1) has a complex water masses structure. It includes the Brazil-Malvinas confluence region, considered one of the most interesting oceanographic region in the world (Souza and Robinson, 2004). The general patterns of deep ocean circulation in the adjacencies of the southern Brazilian coast are reasonably well understood and documented. Tough, the circulation over the wide continental shelf remains poorly studied and virtually unknown
(Zavialov et al., 2002). The local dynamics is peculiar for the large inputs of continental, sub Antarctic and tropical water masses and shows high seasonal variability of the termohaline characteristics (Souza and Robinson, 2004).

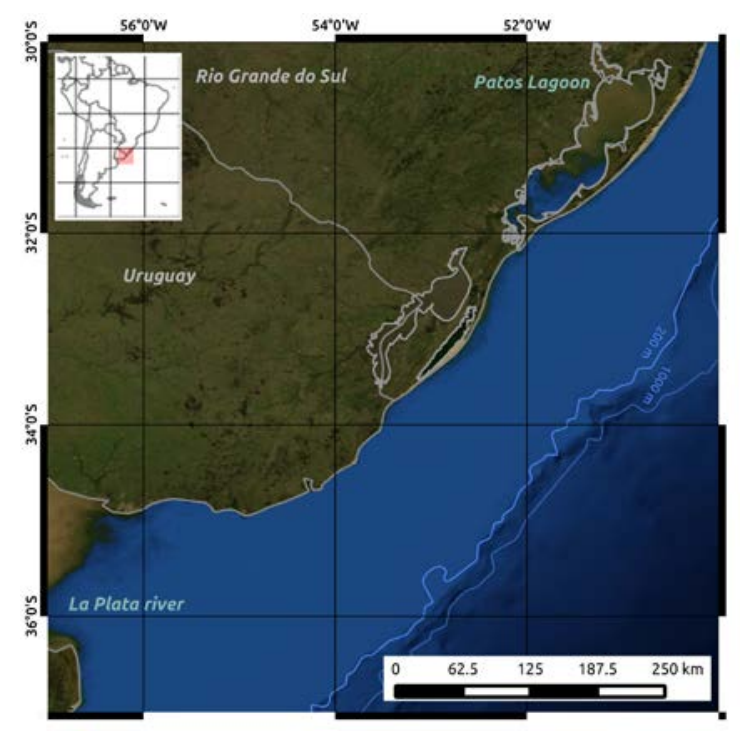

Figure 1. Blue Marble composition of the study area, showing the Southern Brazilian and Uruguayan continental shelves. 
Zavialov et al (2002) performed the first direct measurements of current velocities on the Rio Grande do Sul continental shelf. They described the flow as essentially barotropic, despite the intense depth wise termohaline gradient. A slow northward flow was observed under high continental discharge conditions, independently of the wind direction. This pattern is attributed to the development of a thin and stable brackish water layer at the surface, isolating the water column from the wind stress.

Their analysis showed that the velocities can be described as a sum of highly variable flows, related to the local wind, and a residual flow northwards masked by the local meteorological forcing. It corroborated the study of Soares and Möller (2001), which described the residual flow as shore parallel, equatorward, in agreement with the buoyancy current. However, later measurements carried out by Costa and Möller (2011) during the spring and summer showed that the net flow is southward directed. Such discussions reflect the dynamic complexity of the study area and the need of systematic observations for its understanding.

In this context, the use of remote sensing data is of particular suitability given the good spatial and temporal coverage of the data acquired. The Maximum Cross Correlation (MCC) method has been adapted for the estimation of ocean currents and extensively applied on infrared imagery of deep waters, demonstrating good performances (Oliveira et al., 2005). Garcia and Robinson (1989) showed the efficiency of the MCC method for the continental shelf waters using ocean color imagery acquired by the Coastal Zone Coastal Scanner.

In this paper, we evaluate the suitability of the MCC method for the region comprised between the La Plata river and Patos lagoon estuaries $\left(30^{\circ} \mathrm{S}\right.$ to $37^{\circ} \mathrm{S}, 50^{\circ} \mathrm{W}$ to $57^{\circ} \mathrm{W}$ ), using Moderate Resolution Imaging Spectroradiometer (MODIS) imagery.

\section{THE MAXIMUM CROSS-CORRELATION (MCC) METHOD}

The MCC method applied to MODIS imagery tracks optical features of the ocean's surface, determining their translational movement. The crosscorrelation coefficient is a measurement of the linear relation between two independent variables, which in this case are two bi dimensional images (Gao and Lythe, 1995). The velocity of a feature is given by its relative displacement divided by the time interval between both images.

In each image two sub areas with the same center are defined; the search window (in the first image) and the template window (in the second image). The method searches within the template window for the area with the highest correlation coefficient with the search window. The distance between the center of the search window and the maximum cross-correlated region found in the template window is divided by the time interval between both images, giving a mean velocity vector.

The method requires that the images must be well georeferenced to minimize errors of the features displacement estimates. The maximum time interval between the images should not be longer than 24 hours to prevent errors caused by diffusive processes. The images must have a spatial resolution suitable to the local dynamics, in a way that the features displacement in 24 hours should be larger than the pixel resolution. In order to exclude randomly estimated vectors, it is possible to define a minimum correlation coefficient threshold.

\section{MODIS IMAGERY}

We use the Normalized Water-Leaving Radiance at $550 \mathrm{~nm}$ (NLW550) parameter, once it shows good correlation with sediments in suspension in the water's surface (Otero and Siegel, 2004). The study area receives continental inputs from the La Plata river and the Patos Lagoon estuary, both providing large contributions of suspended matter to the coastal zone. Hence, the tracking of color features formed by the spatial and temporal variability of suspended matter concentration and the local hydrodynamics is feasible in this region. The images were acquired in the processing level L2 - Local Area Coverage (LAC). L2 products are generated after applying the sensor calibration, the atmospheric correction and an algorithm with geophysical parameters on L1 processing level imagery. The geometric corrections were performed using the SeaWiffs Data Analysis System (SeaDAS) software using the Mercator projection.

\section{WIND FIELDS}

We acquire wind data from the ERA-Interim reanalysis project, carried out by the European Centre of Medium-range Weather Forecast (ECMWF), and compare the wind fields with the estimated surface velocity fields. ERAI is the most recent reanalysis release from ECMRWF. It provides data from 1979 to the present in a finest spatial resolution of $80 \mathrm{~km} \mathrm{x}$ $80 \mathrm{~km}$. We acquire the $\mathrm{u}$ and $\mathrm{v}$ wind components at $10 \mathrm{~m}$ above the surface, within the geographical limits of $30 \mathrm{~S}$ to $37 \mathrm{~S}$ and $50 \mathrm{~W}$ to $57 \mathrm{~W}$, for the days that we could obtain current velocity fields using the method proposed.

\section{RESULTS AND DISCUSSION}

We use daily MODIS sensor imagery acquired by the Aqua satellite in 2006 and 2007 for evaluating the method's potential. We selected pairs of images with cloud coverage lower than $50 \%$ in two sequential days, resulting in a series of 48 images (24 pairs). From these, it was possible to estimate surface velocity vectors in 6 pairs, using a minimum 
correlation threshold of 0.65 . Such threshold is relatively low when compared to thresholds used in previous studies. Yet, we tested different values in the range between 0.5 and 1 and selected the one that visually resulted in the best balance between a) the number of vectors estimated and b) the number of spurious vectors estimated. Spurious vectors were removed using a spatial coherence filter, and the resulting vector field was interpolated to a $1000 \mathrm{~m} \mathrm{x}$ $1000 \mathrm{~m}$ regular grid.

The cloud coverage and the diffusive processes are the main limitations for the method in this case. The cloud coverage is usually high in the region, and prevents the ocean surface to be detected by the sensor. The diffusive processes change the spatial patterns of the ocean surface features, restricting their detectability by the MCC. For each image, we used combinations of the size of the search and the template window and selected the combination that generated more vectors in each separate case. Despite the limited number of pairs that generated estimates, the estimates are in agreement with the wind field and the velocities' intensities are well within the values previously described in the literature for the region (Zavialov et al., 2002, Costa and Möller, 2011).

The first image pair is represented in Figure 2. The mean velocity for the day was $0.06 \mathrm{~m} / \mathrm{s}$ yet maximum values reached $0.13 \mathrm{~m} / \mathrm{s}$. The preferential direction of the $\mathrm{v}$ component is northward, in agreement with the wind field. The u component of both current and wind are also in agreement, with preferential direction westward. Such wind conditions are normally caused by the passage of frontal systems over the study area.
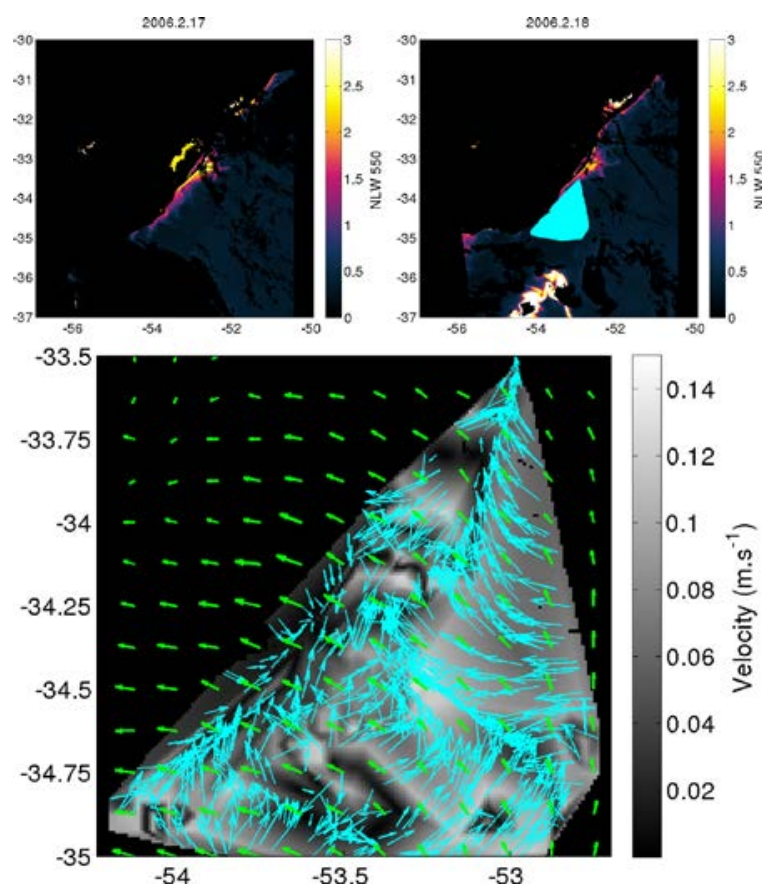

Figure 2. Surface velocity field obtained from the image pair acquired on 17 and 18 February 2016.
The top panels represent the NLW550 parameter for each image. In the lower panel the surface velocity intensity is represented in the color scale, the current directions are the blue vectors and the wind field is represented by the green vectors.

In 13-14 March 2006 the few estimated vectors show again a preferential direction northwestward, accompanying the wind (Figure 3). The velocity maximum reached $0.08 \mathrm{~m} / \mathrm{s}$ with average of $0.06 \mathrm{~m} / \mathrm{s}$. The conditions are similar to the first pair, though fewer vectors were estimated. The color patterns of the water changed drastically from the first to the second image, which limits the efficiency of the MCC method.
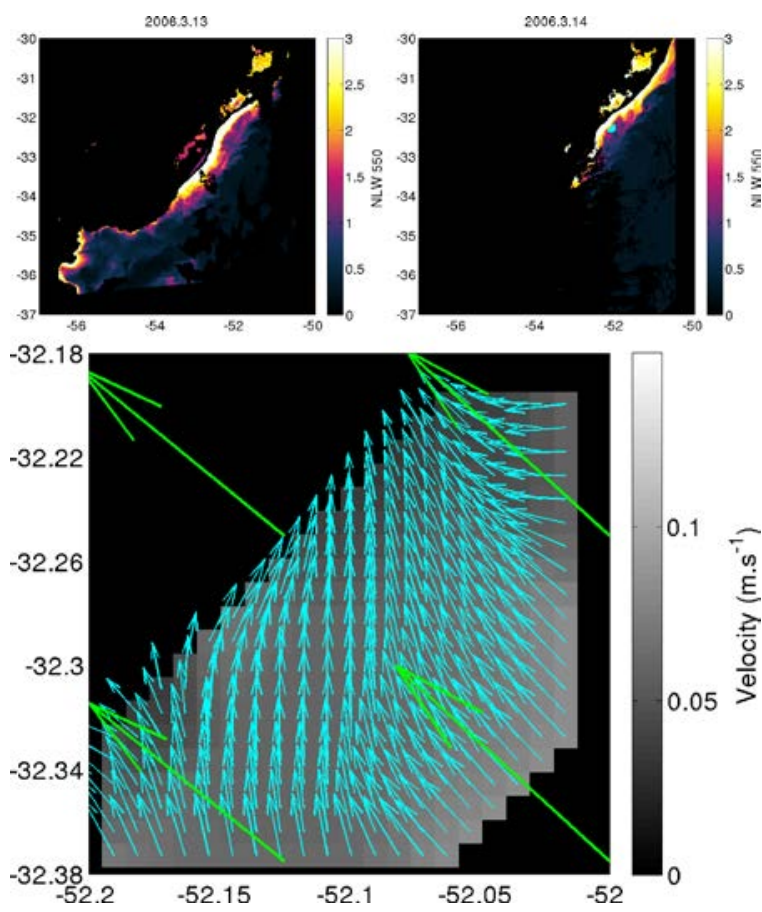

Figure 3. Surface velocity field obtained from the image pair acquired on 13 and 14 March 2006. The top panels represent the NLW550 parameter for each image. In the lower panel the surface velocity intensity is represented in the color scale, the current directions are the blue vectors and the wind field is represented by the green vectors.

The velocity field obtained from the 19-20 July 2006 pair covered a larger area. The estimated vectors were preferentially northeastwards directed (Figure 4). The average wind direction was northeast over the ocean surface, yet the average wind field is not reflecting the prevailing wind direction during the time interval between both images. Figure 5 represents the evolution of the wind field, showing that the prevailing wind was southwest. The average velocity was $0.11 \mathrm{~m} / \mathrm{s}$ with maximum values reaching $0.24 \mathrm{~m} / \mathrm{s}$. According to Zavialov et al (2002), the maximum correlation between the alongshore components of the wind and the currents in this 
region occurs 18 hours after the change of the wind direction.
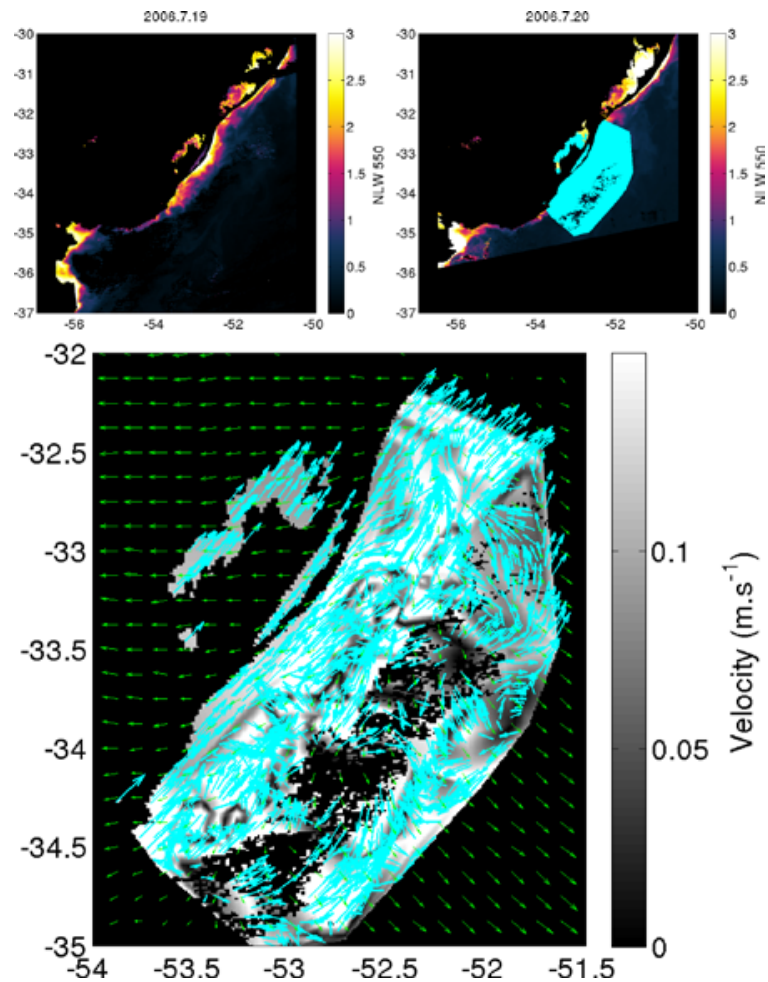

Figure 4. Surface velocity field obtained from the image pair acquired on 19 and 20 July 2006. The top panels represent the NLW550 parameter for each image. In the lower panel the surface velocity

intensity is represented in the color scale, the current directions are the blue vectors and the wind field is represented by the green vectors.
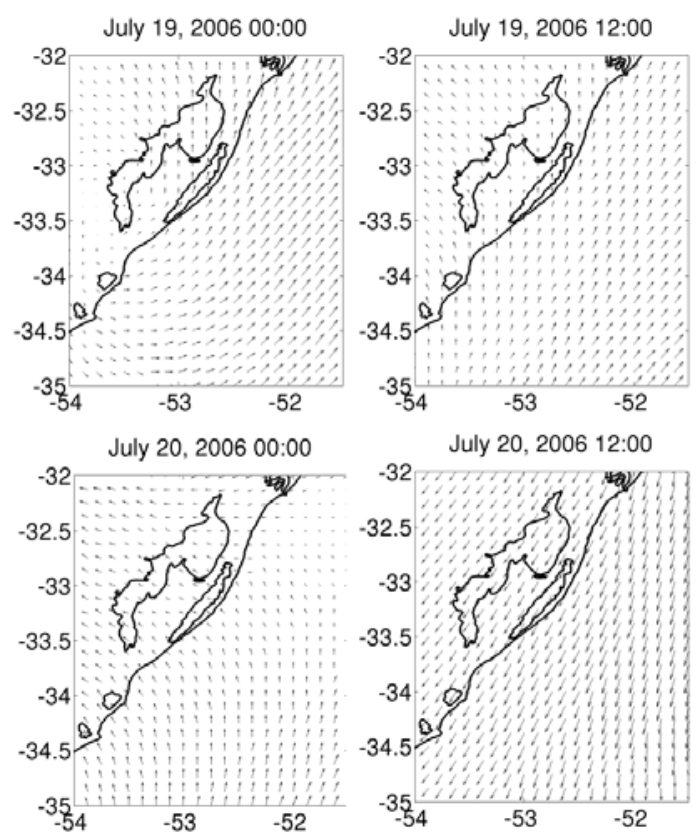

Figure 5. Evolution of the wind field from 19 to 20 July 2006.
The estimates from 28-29 June 2007 were restricted to a small portion of the study area, as the fast change in the color patterns again did not allow for a good method's performance (Figure 6). The average velocity of the homogeneous field was $0.10 \mathrm{~m} / \mathrm{s}$, with maximum of $0.11 \mathrm{~m} / \mathrm{s}$. The current showed direction opposite to the average wind, though in this case the direction of the wind changed from south to east during the 24 hours between both images (Figure 7).

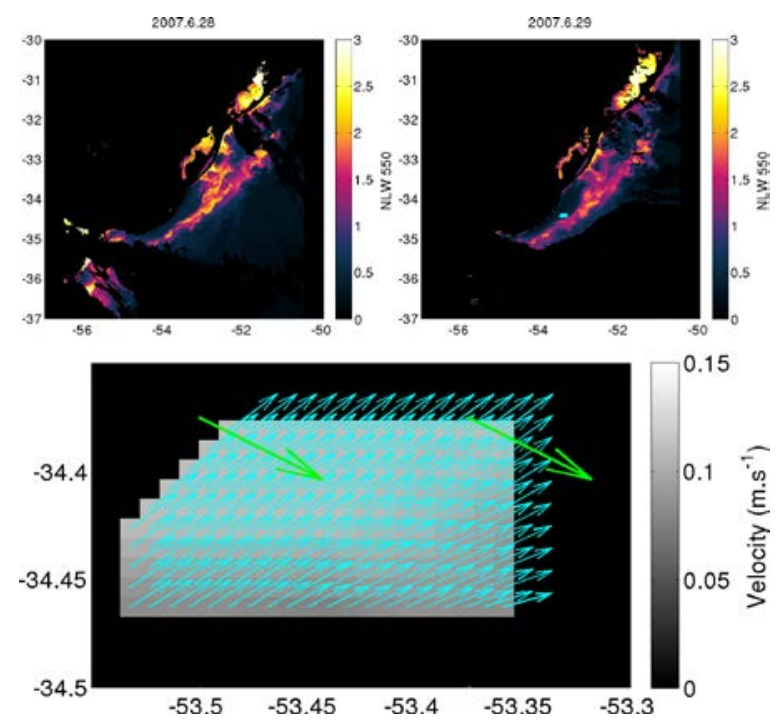

Figure 6. Surface velocity field obtained from the image pair acquired on 28 and 29 June 2007. The top panels represent the NLW550 parameter for each image. In the lower panel the surface velocity intensity is represented in the color scale, the current directions are the blue vectors and the wind field is represented by the green vectors.
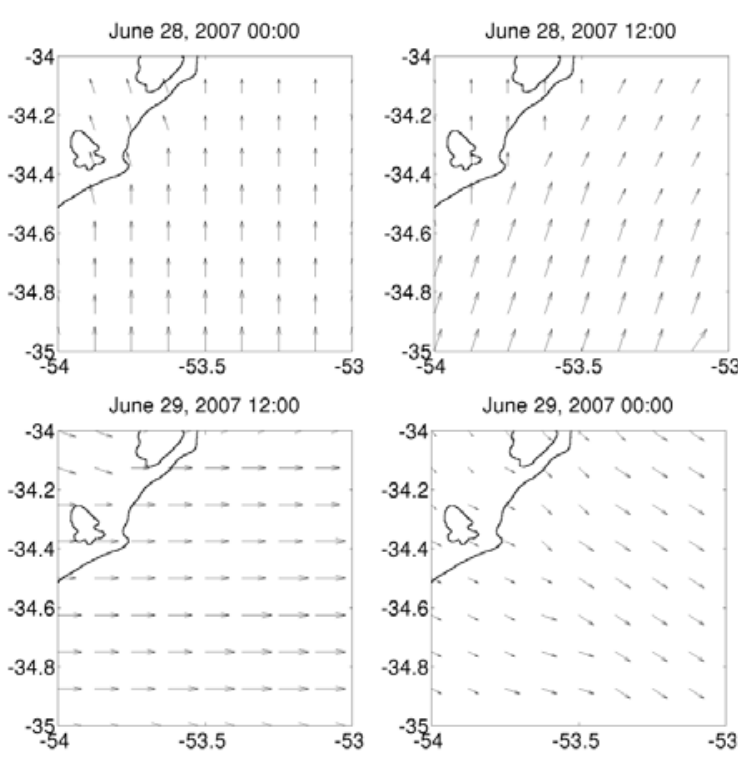

Figure 7. Evolution of the wind field from 28 to 29 June 2007. 
On the 7-8 August 2007 pair, the analysis resulted in a complex vector field, without a single preferential direction of the flow (Figure 8). In the southern portion of the field the current direction is predominantly north, while in the northern portion the vectors are oriented southwards, creating a convergence zone with vectors oriented eastwards at approximately $34.5^{\circ} \mathrm{S}$. The mean and maximum velocities were $0.09 \mathrm{~m} / \mathrm{s}$ and $0.23 \mathrm{~m} / \mathrm{s}$ respectively.
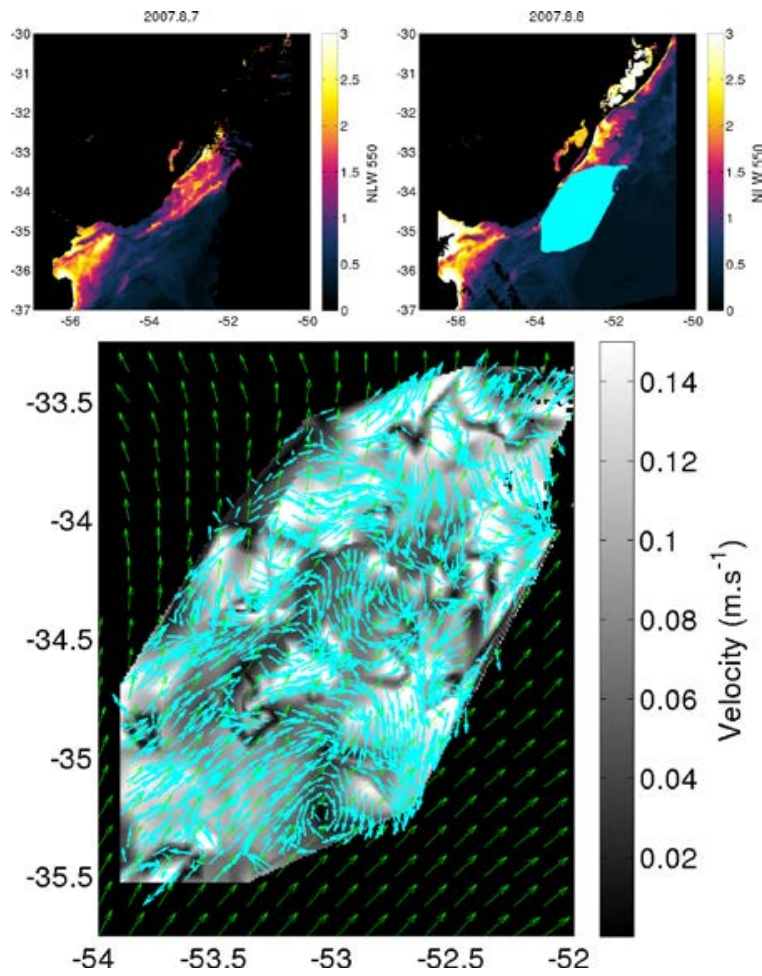

Figure 8. Surface velocity field obtained from the image pair acquired on 7 and 8 August 2007. The top panels represent the NLW550 parameter for each image. In the lower panel the surface velocity intensity is represented in the color scale, the current directions are the blue vectors and the wind field is represented by the green vectors.

The image pair acquired on 27-28 August 2007 also showed two preferential current directions (Figure 9). Similarly to the previous pair, in the northern portion of the field the current has a prevailing south direction, while in the southern part to the north. It creates a similar convergence at approximately $34^{\circ} \mathrm{S}$, suggesting that this may be a frequent feature in the region.

Most of the velocity fields obtained showed a preferential alongshore direction towards north. Although, the fields are in accordance with the wind direction, i.e., most of the images that produced velocity fields were acquired under the influence of winds from the southern quadrants. This is probably due to the typical clear sky conditions that succeed the passage of cold fronts.

The present method does not allow for a frequent monitoring of the study area. Tough, it can be combined with in situ measurements and provide useful information about the spatial distribution of the velocity field. It is also suitable for the validation of hydrodynamic simulations. Considering the very limited knowledge about the dynamics of the region, the logistic difficulties for in situ data acquisition, the method can be considered for further investigations of the continental shelf dynamics. Despite that we selected two years for evaluating the method, it is important to note that MODIS-Aqua imagery is an open access dataset and provides daily imagery of the Earth's surface from 2002 to the present.
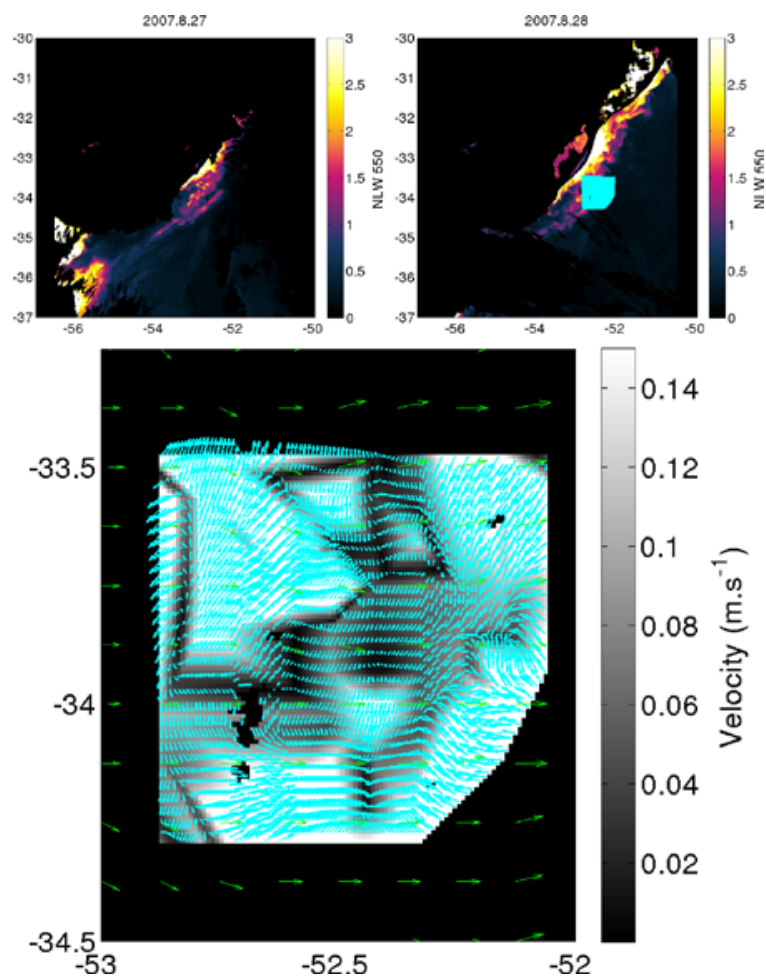

Figure 9. Surface velocity field obtained from the image pair acquired on 27 and 28 August 2007. The top panels represent the NLW550 parameter for each image. In the lower panel the surface velocity

intensity is represented in the color scale, the current directions are the blue vectors and the wind field is represented by the green vectors.

\section{CONCLUSIONS}

The application of the MCC method on sequential MODIS imagery showed potential for estimating the surface velocity fields on the continental shelf. The range of velocity intensities found are in agreement with previous studies, and the directions are in agreement with the wind fields. The method does not allow for a continuous monitoring of the area, once the cloud coverage restricts the data acquisition. Tough, the data generated is spatially distributed, which is an advantage over single point measurements. For this reason, the method may 
provide a valuable dataset for the calibration and validation of hydrodynamic models.

\section{ACKNOWLEDGEMENTS}

The authors acknowledge with gratitude the support of the Coordenação de Aperfeiçoamento de Pessoal de Nível Superior (CAPES) and of the Programa de Formação de Recursos Humanos of the Agência Nacional do Petróleo (PRH-ANP/MCT).

\section{REFERENCES}

Costa, R. L., and Möller, O., 2011, Estudo da Estrutura e da Variabilidade das Correntes na Área da Plataforma Interna ao Largo de Rio Grande (RS, Brasil), no Sudoeste do Atlântico Sul, durante a Primavera-Verão de 2006-2007, Revista da Gestão Costeira Integrada, Vol 11, No. 3, pp. 273-281. (in Portuguese)

Gao, J., and Lythe, M. B., 1996, The maximum Cross-Correlation Approach to detecting Translational Motions from Sequential RemoteSensing Images, Computers and Geosciences, Vol. 22, No. 5, pp. 525-534.

Garcia, C. A. E., and Robinson, I. A. N. S., 1989, Sea Surface Velocities in Shallow Seas Extracted from Sequential Coastal Zone Color Scanner Satellite Data, Journal of Geophysical Research, Vol. 94, No. C9, pp. 681-691.

Oliveira, E. N., Domingues, C. M., and Ghisolfi, R. D., 2005, Velocidades de Corrente a partir de Imagens de Satélite. Em Oceanografia por Satélites, Oficina de textos, São Paulo. (in Portuguese)

Otero, O. P., and Siegel, D. A., 2004, Spatial and Temporal Characteristics of Sediment Plumes and Phytoplankton Blooms in the Santa Barbara Channel, Deep-Sea Research II, Vol. 51, pp. 11291149.

Soares, I., and Möller, O., 2001, LowFrequency Currents and Water Mass Spatial Distribution on the Southern Brazilian Shelf, Continental Shelf Research, Vol. 21, pp. 1785-1814.

Souza, R. B., and Robinson, I. S., 2004, Lagrangian and Satellite Observations of the Brazilian Coastal Current, Continental Shelf Research, Vol. 24, pp. 241-262.

Zavialov, P., Möller, O., and Campo, E., 2002, First Direct Measurements of Currents on the Continental Shelf of Southern Brazil, Continental Shelf Research, Vol. 22, pp. 1975-1986. 